\title{
Prevention of Infant'S Otic Barotrauma - Observing the Infant Prior to Air Travel and Identifying Infants Less Likely At Risk
}

\author{
Klaus Martin Beckmann \\ School of Medicine, Griffith University, Logan Campus, Queensland \\ *Corresponding Author: martinbeckmannnn@hotmail.com
}

Copyright (C) 2013 Horizon Research Publishing All rights reserved.

\begin{abstract}
Otic barotrauma is a potential risk for travelers using commercial aircraft. A significant proportion of passengers are infants. No literature exists regarding pre-flight assessment for prevention of barotrauma in infants due to air travel. Infants are preverbal in their development and cannot communicate their distress with words, though will show age-typical distress and pain responses. Pain and concomitant trauma, where possible, are ideally prevented. This paper suggests that it may be possible for parents to detect prior to flight whether their infant is likely to suffer pain from Eustachian tube malfunction with in-flight cabin pressure changes. This may be achieved by co-incidental observation of infants and their subsequent distress with small rapid air pressure change, such as in rapid elevator ascent/descent, which elicits "ear popping" in the parents. This may help predict a healthy infant's response to change in air pressure during air travel. A case example is given. Barotrauma in the context of the infant's neuropsychology is described and relevant literature to the topic is reviewed.
\end{abstract}

Keywords Infant, Ear, Air Travel, Barotrauma, Prevention.

\section{Introduction}

Worldwide airlines transport over 1.25 billion passengers per year [1]. A significant proportion of those passengers are infants. Infants for developmental reason cannot equalise ear pressure in the same way as older children and adults who for example can initiate a Valsalva maneuver. Hence infants may be at even greater risk of discomfort, ear pain and barotrauma. With repeated episodes of barotrauma infants may be at risk of longer lasting sequelae of physical and psychological trauma.

Numerous guidelines offer advice on how to prevent barotrauma and how to address air pressure changes in flight.
However to the author's best knowledge and after review of the literature it appears that so far no infant specific advice how to prevent otic barotrauma is available. It appears that a simple method to identify a subgroup of infants not at risk of barotrauma from Eustachian tube dysfunction has so far not been suggested.

There is reference to a case example of one. Coincidental pre-flight observation assessing Eustachian tube function can indicate patent Eustachian tube. The suggestion is to use a coincidental empirical observation on how the infant reacts to small air pressure changes of around $15 \mathrm{mmHg}$ (a height differential of over 100 meters). At an increase of $15 \mathrm{mmHg}$ the Eustachian tube passively opens and vents of positive pressure; at a reduction by $15 \mathrm{mmHg}$ diverse effects will balance negative pressure.

\section{Materials and Methods}

A literature review was performed in May 2013 on PubMed, Informit, Uptodate, Google Scholar and National Centre for Biotechnology Information using key words "infant, ear, barotrauma, prevention, air travel". A summary of relevant findings from this search and background information is provided. This draws on papers previously published on the subject across age-groups, not limited to infancy.

This paper reports the case of one infant subject to change in air pressure in an every-day coincidental empirical observation and the subsequent response to air pressure changes in an aircraft and then refers to findings from research relating to psychological trauma in infants.

\section{Results}

\subsection{Literature Review - barotrauma}

A literature search with the key words "infant, ear, 
barotrauma, prevention, air travel" did not yield any relevant papers regarding infants and barotrauma. References yielded papers relevant to the broader context of barotrauma in children and adults. This is likely the first paper that connects these keywords and specifically investigates air pressure changes, pain and its psychological effects in the infant, and use of an observation that identifies infants who have a patent Eustachian tube.

One paper on prevention, barotrauma and the middle ear in German language was found, provided by the publisher upon request [2] and not available online.

Numerous papers were found that address ear problems associated with scuba and Deep Sea diving, blast injuries, physical trauma, hyperbaric oxygen therapy, space medicine and sky diving and are not referred to in this article.

\subsubsection{Barotrauma - the Historical Context}

Anatomist Eustachio [6] described the Eustachian tube in the 15th century. In adults this tube, which reaches from the middle ear to the nasopharynx, is around $3.75 \mathrm{~cm}$ long. Boyle [7] in 1662 and Marriotte [8] in 1676 confirmed independently from each other by experiment the relationship between pressure and volume. Valsalva [9] described the eponymous maneuver in 1704: this involves forced expiration with lips and nostrils closed, hence increasing air pressure in the nasopharynx, forcing air along the Eustachian tubes and thereby increasing pressure in the middle ear. The first description of barotrauma was given by Charles [10] in 1783. He was the first person to make a free ascent in a hydrogen balloon and complained of severe pain in his right ear during descent. Corti [11] described the eponymous organ in 1851. In 1860 Toynbee[12] described how pinching the nose and swallowing can relieve ear discomfort due to pressure differential. Politzer [13] in 1861 developed a method to inflate the middle ear by increasing pressure in the nasopharynx with the assistance of a rubber balloon and asking the patient to swallow. In 1938 Frenzel [14] described a maneuver used by pilots: saying the letter " $\mathrm{k}$ " whilst closing nose, mouth and glottis as if lifting heavy weights. The advantage of Frenzel maneuver in flight is that it can be performed both during expiration and inspiration, although requires some training to learn the technique.

\subsubsection{Anatomy and Physiology Associated with Eustachian Tube}

The middle ear is filled with air. It is separated from the outside world, on the one side by the tympanic membrane and on the other side by the Eustachian tube. Middle ear pressure ideally is similar to the pressure of the outside world. If conditions are right the tympanic membrane can vibrate and sounds are clear. Any air in the middle ear can get absorbed albeit slowly. If healthy the Eustachian tube is mostly closed, to prevent motion of the tympanic membrane, and opens only briefly and allows movement of air. During swallowing, crying, yawning, it opens briefly. Muscles which lift and tense the palate are responsible for opening the Eustachian tube. The inner ear is filled with lymphatic fluid and connects with the middle ear via the oval and the round window.

\subsubsection{Epidemiology of Barotrauma}

There is no research data on ear problems associated with air travel in infants. However sufficient data are available confirming high prevalence of otalgia associated with air travel in children and adults. Stangerup et al [15] find that $65 \%$ of children and $46 \%$ of adults report ear discomfort or pain during previous flights and for a single flight $26-55 \%$ of children and $20 \%$ of adults report ear pain. Buchanan et al [16] find that on a single flight $31 \%$ of children experience pain or discomfort during ascent and $85 \%$ during descent. Lewis [17] finds in healthy air crews the incidence of barotrauma ranges between 1.9 and $9 \%$. Morgagni et al [18] find that amongst 314 individuals there were 7 men who had acute barotitis (incidence of $2.3 \%$ ) and 28 men who had delayed ear pain (incidence of $9.2 \%$ ). This research was done in hypobaric chambers using 2 altitude training profiles of around 35,000 feet $(10,668$ meters) and 25,000 feet ( 7620 meters). Moore et al [19] report 222 pre-flight and in-flight emergencies, representing $9.2 \%$ from amongst their database. They estimate 1 paediatric emergency call in 20775 flights. The most common and 27\% (45 calls) of all emergencies were due to infectious diseases, fever and otitis media. Aerospace Medical Association [20] reports that $62 \%$ of in-flight emergencies were associated with pre-flight morbidities.

\subsubsection{Pathophysiology of Otic Barotrauma}

Rapid or significant changes of air pressure can lead to middle ear discomfort, pain and barotrauma. Failure to facilitate balanced air pressure may distort and stretch the tympanic membrane, causing bleeding into the membrane, fluid exudates in the middle ear and possible tympanic membrane rupture. Magnified pressure may be exerted onto the auditory ossicles with resultant damage. Pressure magnified by a factor of 20-30 may also be conducted onto the oval window, due to the hydraulic effect of the tympanic membrane being much larger than the oval window. This pressure can damage the Reissner's membrane of the cochlea. Occasionally with severe pressure changes the round window is ruptured. With open round and oval windows lymph fluid may leave the Organ of Corti with resultant neural cell loss and likely inner ear hearing loss.

\subsubsection{Aetiology of Otic Barotrauma}

Failure of the Eustachian tube can occur for a variety of reasons. There are some conditions that make barotrauma, due to Eustachian tube failure, more likely. Oedematous mucosa due to upper respiratory tract infection or allergy in the nasopharynx will obstruct the lumen of the Eustachian tube. Appropriate middle ear ventilation may also be impaired by enlarged adenoids or nasopharyngeal tumours. Nakashima et al [21] found in 3 out of 8 patients with barotrauma had no jugular fossa and postulated a link.

Flying is the most frequent cause of barotrauma [22, 23]. 
Above 22500 feet altitude cabin pressure is always decreased [24]. Cabin air pressure is adjusted whilst the outside barometric pressure decreases as the plane ascends. Inner ear pressure can be equilibrated by swallowing, crying or yawning but also, in a limited way, by absorption of air by the middle ear mucosa. This is different on descent: air pressure has to increase in the middle ear in order to balance the increase in atmospheric pressure.

A well-functioning ear can easily tolerate and equalise air pressure between outer ear and middle ear. Risk for otic damage increases when equalising in the early stages of increase of pressure on descent does not occur. There is a point when the muscular actions of the Eustachian tube can no longer override the deficit of pressure in middle ear. Once beyond this point greater otic damage is inevitable. Bielenberg [2] suggests that with 60 millimeter of mercury or " $\mathrm{mmHg}$ " ( 80 hectopascal or " $\mathrm{hPa}$ ") difference in pressure the individual will subjectively experience unpleasant sensations of pressure. At $90 \mathrm{mmHg}(120 \mathrm{hPa})$ it is no longer physiologically possible to equalise the pressures. The individual experiences severe pain. $100-150 \mathrm{mmHg}(133.3$ - $200 \mathrm{hPa}$ ) leads to rupture of the tympanic membrane, hearing loss, vertigo, vomiting and nausea.

Most commercial aircraft have a pressure differential of $80 \mathrm{mmHg}(106.6 \mathrm{hPa})$. Kortschot et al [25] report that aircraft such as Boing 737 have a greater pressure differential and barotrauma is more likely with these aircraft. They also suggest that a tympanogram performed immediately after Toynbee test showing no increase in negative pressure, may identify Eustachian tube dysfunction and vulnerability to barotrauma. However Ashton et al [26] suggest that tympanometry prior to altitude exposure does not add because tests reflect Eustachian tube patency only at an instant.

\subsubsection{Changes in Air Pressure and Implications for Otic Trauma}

Brown [22] found that a healthy ear will vent expanding air at a pressure differential of $15 \mathrm{mmHg}$. The Eustachian tube opens at $15 \mathrm{mmHg}$ when the pressure is lower on the outside. In flight this occurs during ascent. $15 \mathrm{mmHg}(20 \mathrm{hPa})$ is equivalent to a difference in altitude of 122 meters. On the ground air pressure is $756 \mathrm{mmHg}(1013 \mathrm{hPa})$ and in-flight cabin air pressure is adjusted to $562.5 \mathrm{mmHg}(750 \mathrm{hPa})$ which is equivalent to an altitude of 2450 meters. Schmitz [27] describes how speed of air pressure change is 13.7 $\mathrm{mmHg}(18.3 \mathrm{hPa})$ per minute during ascent and $8.25 \mathrm{mmHg}$ $(11.0 \mathrm{hPa})$ per minute during descent. King [28] shows that the severity of barotrauma depends on the rate of $\mathrm{mmHg}$ $(\mathrm{hPa})$ change per minute.

Hence air emergencies and events such as loss of cabin pressure that make pressure changes rapid and greater are likely to increase the risk and severity of otic trauma. It is important to stay awake during descent and ascent so pressures can be adjusted at intervals small enough that no barotrauma develops.

Typically a patient exposed to different air pressures in the middle ear/outer ear will complain of a subjective sensation of pressure or blockage in the ear [29, 30]. King [28] describes how the tympanic membrane bulges to its limits in flight when the passenger does not swallow. Pain ensues with increasing pressure differential.

\subsubsection{Prognosis of Barotrauma}

Ear discomfort, pain and sequelae of barotrauma such as oedematous and/or hemorrhagic ear drums, serous or hemorrhagic otitis and tympanic membrane ruptures typically remit over time once Eustachian tube function is restored. Ossicular disruption can lead to persistent conductive hearing loss. Vertigo and sensorineural hearing loss can ensue from damage to the round or oval window. Pulsating tinnitus may be another consequence but normally resolves with reabsorption of oedema and serous effusion. Constant tinnitus however does not always resolve and may be permanent.

Surgical intervention by tympanoplasty or patching of the round or oval windows may be required in severe barotrauma. Mild barotrauma is managed conservatively [31]. There is no convincing evidence that corticosteroids, decongestants or antihistamines accelerate recovery from barotrauma.

\subsubsection{Common Subjective Observation on the Function of Eustachian Tube}

Most individuals will know ear discomfort arising from pressure changes when overcoming significant height difference, when for example using a lift or travelling up or down in mountains. The difference in height and the speed of vertical movement are relevant to the quality of the subjective experience. If discomfort does not disappear on its own, usually an individual will adjust to pressure changes by using a sweet, opening the jaw, chewing, swallowing, yawning or doing a Valsalva maneuver

\subsubsection{Prevention of flight-related barotrauma}

Avoiding flying is a frequent prudent recommendation in the case of upper respiratory tract infections and ear infections [22]. If travel is deemed unavoidable then measures to open the Eustachian tube could be used: regularly yawn, swallow, chew and perform the Valsalva maneuver on ascent and particularly descent. Infants normally will be able balance pressures between middle and outer ear when swallowing, chewing crying or yawning. Byers [32] recommends that parents bottle feed the infant in-flight when the parents feel the need to clear their ear. Typically infants cry within 9 minutes of the parent's feeling of the need to equalise. Hanna [33] recommends equilibrating middle ear pressure at least 3-4 times to prevent barotrauma. Buchanan et al [15] advocate using a warm wet towel over the external ear to decrease "ambient" ear pressure.

Badiee et al [34] recently report the successful use of the smell of maternal breast milk to reduce pain during a painful procedure (heel lancing) in preterm newborns. It could be 
speculated that the smell of maternal milk may subjectively reduce pain or discomfort experienced in-flight. Regardless, the sucking movements of breast feeding in-flight will certainly have the same effects as bottle feeding on equalisation of ear pressure.

Special ear plugs that moderate pressure changes are available, though these have a limited role and are not indicated in infants [35].The benefits of inhaling surfactant are currently being evaluated [36]. Other studies investigate the role of decompression in near zero gravity environments in reducing the incidence of barotrauma [37]. Patients who undergo hyperbaric treatments, for example wound healing, may benefit from insertion of ventilation tubes. This may be also be an intervention to give long lasting relief for patients who have Eustachian tube problems and must fly frequently $[38,39]$.

\subsection{Review - Development, Psychological Sequelae of Pain and Psychological Trauma}

Relevant findings from the adult and child literature about barotrauma are summarised and reference is made to infant health and mental health where relevant.

It is important to separate infant mental and physical health from child, adolescent and adult physical and mental health

Freud [3], Piaget [4] and Erikson [5] are some of the most famous researchers who describe the different psychological developmental stages and associated needs after birth.

\subsubsection{Psychology, Pain and Trauma in the Infant}

Physical health trauma may have psychological sequelae, with some infants more vulnerable to sequelae than others. Schore [40] comments on the time frame for recovery after trauma: "it can take hours or days or even weeks or longer for certain personalities experiencing extremely intense negative emotion to get back to 'normal state' again". Adamec et al [41] highlight how brief stress may have an impact: "neuroplasticity in right hemispheric limbic circuitry in mediating long lasting changes in negative affect following brief but severe stress". Schutz [42] underlines the importance of the right hemisphere preferentially processing environmental challenge, stress and pain and managing self-protective responses such as avoidance and escape.

Glaser et al [43] highlight hypervigilance after early trauma stating that emotional stress reactivity is most pronounced for subjects who experience trauma at an early age. Early trauma may have enduring effects on adult psychological functioning, with continual response to small stressors occurring in everyday life. Watt et al [44] comment on the link of psychological stresses and brain growth. Kehoe et al [45] link early experiences with pattern of behaviours later in life: "events experienced early in life may be particularly important in shaping the individual's pattern of responsiveness in later stages of life".

Brain growth is greatest in the first years of life, more than doubling in volume in the first year of life. Knickmeyer et al
[46] suggests that "this is a critical period in which disruption of developmental processes, as a result of innate genetic abnormalities or as a consequence of environmental insults, may have long lasting or permanent effects on brain structure and function".

The effects of adverse events on infants are relevant in the context of the left brain-right brain divide. The left hemisphere is largely responsible for speech and the right hemisphere more responsible for emotions. Infants typically do not have verbal language; toddlers regularly start using more than just a few words after their second birthday. Earliest trauma is going to lead to non-verbal, pre-verbal memories. Gadea et al [47] comment on the effect of mild to moderate negative experiences resulting in right hemisphere processing activation (and attentional bias to the left ear). Schuetz \& Reid [48] showed lateralisation of negative emotional production to the right hemisphere in infants as young as 12 months of age following adverse effects.

\subsubsection{Intersubjectivity}

During the first months and years of an infants and toddlers life the relationship between parent, especially the mother, and the infant is crucial. Byers [32] described how 4 out of 22 mothers with a crying infant during descent attributed the crying to ear pain. Parents can use good attunement and understanding of the infant's internal world to soften the after effects of pain and psychological trauma.

Learning during the first months and years is exponential. An infant can learn a helpful pain response via vicarious learning. Schore [49] states that "events that occur during infancy, especially transactions with the social environment, are indelibly imprinted into the structures that are maturing in the first years of life." Gogate et al [50] highlight the role of maternal-infant interactions: "from birth an infant is plunged into a world of other human beings in which conversation, gestures, and faces are omnipresent during the infant's waking hours. Moreover these harbingers of social information are dynamic, multimodal and reciprocal." Ovtscharoff et al [51] highlight the dynamic quality of the parent infant interaction: "the dyadic interaction between the newborn and the mother constantly controls and modulates the newborn's exposure to environmental stimuli and thereby serves as a regulator of the developing individual's internal homoeostasis." Hence a parent or other caregiver can psychologically assist the infant coping with distress and pain. The parent may continue to be attentive and provide an example with their own behaviour, by appearing not distressed themselves.

\subsubsection{Stages of pain response in infants}

There are several tools that identify stages of pain in infants. The preterm infant pain profile (PIPP) [54] in its non revised version is freely available online. PIPP identifies 4 severity levels of infant pain. Parent's observations could be linked with PIPP findings and drawings of facial "indicators" (Box 1) which include:

- Activity level of the infant from quiet and no facial 
movement, to active with eyes open and facial movements.

- Stable baseline heart rate to an increase of more than 24 beats per minute over baseline heart rate,

- No brow bulge to maximum brow bulge

- No eye squeeze to maximum eye squeeze

- No nasolabial furrow to maximum nasolabial furrow.

PIPP has originally been developed for medical purposes i.e. to assist clinicians and researchers in assessing infants in hospital settings. For the parent and especially in flight it is clearly not feasible to do formal measurements of parameters. However the other domains of activity level, brow bulge, eye squeeze, nasolabial furrow can be assessed at first glance. It is possible for parents to form an opinion of the severity of the distress in their infant by using parts of the PIPP.

\subsection{Case history}

Parental consent was obtained. One 3 month old infant was observed during use of an elevator in a skyscraper of 35 floors (135 meters / 443 feet) ascending and descending in one go to and from the 32 nd floor. The parents both had the subjective experience of the parent's "ear popping" on both ascent and descent. Both parents relieved the discomfort of inner ear pressure change with a Valsalva maneuver. The healthy infant with an otherwise functional Eustachian tube and for developmental reasons not capable of Valsalva was not distressed during the use of the lift or for 15 minutes thereafter. The parents concluded that the infant was able to cope with the pressure differential without distress. At 4 months of age the infant travelled extensively with 8 international flights over a 4 week period in Boing 747s and 777 aircraft. On the PIPP the parents scored the infant at 0 points during the observation at $15 \mathrm{mmHg}$ pressure differential, and during all in-flight ascents and descents. The mandated use of infant seat belts precluded the possibility of breastfeeding during ascents or descents and despite this there had been no discernible distress. In addition, there had been no intercurrent respiratory tract infections.

\subsubsection{Case history - limitations}

A case number of one in itself does not allow extrapolation to the great number of infants travelling in aircrafts. However it is not surprising that there is so little published on otic trauma in infants. History taking for infants relies on informants and their observations which are likely biased. Ethics approval is unlikely to be obtained if it is about exposing infants to pain. Moreover it is unlikely to find parents or guardian volunteers to contribute to formal research that looks at response to pain in infants. However parents can opportunistically observe infants during the parent's coincidental subjective experience of "ear popping".

A variance that cannot be accounted for when talking about pressure differential is speed of pressure change. The speed of pressure change significantly contributes to the subjective experience in the middle ear and pathology. In-flight pressure change is standardised. During the pre-flight coincidental observation parents with infants may be exposed to faster, same or slower pressure changes compared to in an aircraft. The speed of change in pressure will not be easily standardised in this coincidental observation.

\subsubsection{Case History - Recommendation}

Recommendation is limited to coincidentally observe an infant at a differential in altitude of 122 meters or $15 \mathrm{mmHg}$. Whilst parents may be reassured that their infant has a functional Eustachian tube because the infant is not distressed, the corollary does not hold. If an infant is distressed this may be due to a multitude of reasons and cannot be positively attributed to a non functional Eustachian tube.

\section{Discussion}

Generally flying is safe for passengers including infants. However, infants unable to equalise may experience ear pain on aircraft descent or ascent. Infants with a pre-existing middle ear condition are at particular risk of barotrauma. Infants cannot communicate their distress with words as older children can. Moreover infants with barotrauma may develop long lasting adverse consequences on hearing ability and neurological wiring of the brain, secondary to the stress associated with pain. Such otic and neuro- psychological damage may lead to a reduction in functioning. This can be associated with handicap and impairment, which can be associated with costs to the individual and also the economy.

This is likely the first paper that describes barotrauma in the context of the infant's neuro- psychology and describes an easily accessible observational tool to help assess whether the infant's Eustachian tube is patent. Parents can opportunistically observe infants during the parent's coincidental subjective experience of "ear popping" due to rapid ascent/descent in elevators. This may help predict a healthy infant's response to change in air pressure during air travel.

However, identifying infants who tolerate air pressure changes and are capable of equalising may not necessarily predict those who do not develop symptoms of ear pain. Gutowitz et al [52] showed that the rapid descent in skydivers caused negative middle ear pressure changes but that these were not associated with the presence of middle ear symptoms i.e. those who developed middle ear symptoms did not have significantly different ear pressure changes from those who had no symptoms.

Implementation of this observational tool should be applied only in healthy infants since responses may be unpredictable in the presence of ear pathology. Weiss et al [53] report on 14 children who had middle ear effusion pre-flight. Fluid does not expand like air hence should be protective. Air-fluid levels proved protective in 3 children. In 2 children the opposite ear developed otic barotrauma.

Some recommendations for prevention of barotrauma 
found in literature while specific for children may be adapted to infants. Recommendations include strategies such as remaining awake during times of change in cabin pressure, aiding the opening of the Eustachian tube by feeding and promoting swallowing and not travelling in the case of known upper respiratory tract infection or other pathology that affects the functionality of the Eustachian tube.

\section{Conclusion}

Application of a simple observational tool of infant's response to pressure changes prior to air travel may help predict a healthy infant's response to in-flight air pressure change. This may be achieved by observation of infant distress during the parent's coincidental subjective experience of "ear popping" due to exposure to a pressure differential of $15 \mathrm{mmHg}$. The utility of such an approach requires further appraisal. Prevention of pain or discomfort is important not only in averting physical effects of barotrauma but possibly also in the neuropsychological development of the infant. The main limitations of this article are the lack of advice on how to proceed if the infant shows evidence of distress and the limitation of extrapolating from a single case report. It is likely that an observation as suggested will have high sensitivity in a pathology free child who does not show distress with pressure change. Specificity in such a case however is likely going to be low. A study comprised of a series of co-incidental observations of infants subjected to pressure change is required in order to draw more robust conclusions.

\section{Acknowledgements}

I wish to thank the Australian Childhood foundation for inviting Allan Schore to present in 2009 and providing handouts. I also thank librarian Jeremy van Dorsselear for assisting with the literature search.'

\section{REFERENCES}

[1] Peterson DC, Martin-Gill C, Guyette FX, et al. Outcomes of medical emergencies on commercial airline flights. N Engl J Med. May 30, 368 (22): 2075-2083; 2013.

[2] Bielenberg J. Barotraumen des Mittelohres bei Kindern; Praeventive Massnahmen gegen Aerotitis media.Kinderkrankenschwester. (in german) Nr.6. 2011.

[3] Freud S. The standard edition of the complete psychological works of Sigmund Freud.

[4] Strachey, J (Ed). Oxford, England: Macmillan;1964.

[5] Piaget J. Cognitive development in children: Piaget development and learning. Journal of research in science teaching; 1964.
[6] Erikson, E. Ego development and historical change.The Psychoanalytic Study of the Child. Vol 2, 359-396;1946.

[7] Roberts, K B. "Eustachius and his anatomical plates." Newsletter of the Canadian Society for the History of Medicine, Apr.: 9-13; 1979.

[8] Cardwell, DSL. From Watt to Clausius: The Rise of Thermodynamics in the Early Industrial Age. London: Heinemann;1971.

[9] Chisholm, Hugh, ed. "Mariotte, Edme". Encyclopædia Britannica (11th ed.). Cambridge University Press; 1911.

[10] Van Gijn J, Gijselhart J P. "Antonio Maria Valsalva (1666-1723) and his manoeuvre". Ned Tijdschr Geneeskd (in dutch) (Netherlands) 154: A1803; 2010.

[11] Needham, J. Science and Civilization in China: Volume 4, Physics and Physical Technology, Part 2, Mechanical Engineering. Taipei: Caves Books Ltd;1986.

[12] Kley, W. "Alfonso Corti (1822-1876)--discoverer of the sensory end organ of hearing in Würzburg". ORL J. Otorhinolaryngol. Relat. Spec. (Switzerland) 48 (2): $61-7 ; 1986$.

[13] Betlejewski, S, Betlejewski, A. "Joseph Toynbee--otologist, scientist, philanthropist". Otolaryngologia polska. the Polish otolaryngology (in pol) 63 (2): 199-203; 2009.

[14] Die Beleuchtungsbilder des Trommelfells im gesunden und kranken Zustande. Wien, W. Braumüller, 1865. English translation, New York, 1869

[15] Brubakk A O,Neuman T S. Bennett and Elliott's physiology and medicine of diving, 5th Rev ed. United States: Saunders Ltd. p. 800; 2003.

[16] Stangerup SE, Tjernström O, Klokker M, Harcourt J, Stokholm J. Point prevalence of barotitis in children and adults after flight, and effect of autoinflation. Aviat Space Environ Med. Jan;69(1):45-9; 1998.

[17] Buchanan BJ, Hoagland J, Fisher PR. Pseudoephedrine and air travel associated ear pain in children.Arch Pediatr Adolesc Med; 153;466-8;1999.

[18] Lewis ST. Barotrauma in United States Air Force accidents/ incidents. Aerospace Med. 44, 1059- 61; 1974.

[19] Mortgagni F. Autore A. Landolfi A. Ciniglio Appiani M. Appiani GC. Predictors of ear barotrauma in aircrews exposed to simulated high altitude. Aviation Space \& Environmental medicine. 83 (6); 594-7, 2012.

[20] Moore BR, Ping JM, Claypool DW. Pediatric Emergencies on a US based Commercial Airline. Pediatric Emergency Care. Vol 21, no 11,725 -29; 2005.

[21] Aerospace Medical Association, Air transport Medicine committee. Medical Guidelines for air travel. Aviat Space Environ Med. 71, 832-38; 2000.

[22] Nakashima T, Yanagita N, Yamakawa K, Naganawa S. Inner ear barotraumas: computed tomogram evaluation. Clin Otol.20: 544-46; 1995

[23] Brown TP. Middle ear symptoms while flying. Ways to prevent a severe outcome. Postgrad Med. 96:135; 1994

[24] Rosenkvist L, Klokker M, Katholm M. Upper respiratory 
infections and barotraumas in commercial pilots: a retrospective survey. Aviat Space Environ Med.79:960; 2008.

[25] AMA Commission on Emergency Medical Services.Medical aspects of transportation aboard commercial aircraft. JAMA. 246,1007-11; 1982.

[26] Kortschot HW, Oosterveld WJ. Barotrauma in Boing 737 cabin crew. Otorhinolaryngol Rel Spec.55,144-16;1993.

[27] Ashton DH, Watson LA. The use of tympanometry in predicting otitic barotraumas. Aviat Space Environ Med. 61, $56-61 ; 1990$.

[28] Schmitz G. Klimatisieren von Flugzeug Kabinen. Technische universitaet Hamburg Harburg. 15.01.2004. [cited 15 .07.2013] Available from: http://www.fzt.haw-hamburg.de/pers/Scholz/dglr/hh/text_20 04_01\%20_15_Klimatisierung.pdf

[29] P.F. King The Eustachian tube and its significance in flight. The Journal of Laryngology and Otology. 93: 659-678; 1979

[30] Sato S, Yokoi H, Fukuta S, et al. Morphological studies on middle ear barotrauma in guinea pigs. Nagoya J Med Sci ; 60:109; 1997.

[31] Strohm M. Trauma of the middle ear. Clinical findings, postmortem observations and results of experimental studies. Adv Otorhinolaryngol. 35:1;1986.

[32] Parell GJ, Becker GD. Conservative management of inner ear barotrauma resulting from scuba diving. Otolaryngol Head Neck Surg. 93:393; 1985.

[33] Byers PH. Infant crying during aircraft descent. Nurs res. $35 ; 260-2.1986$.

[34] Hanna HH. Aviation aspects of otolaryngology. Otolaryngology:JB Lippincott.1-17; 1989.

[35] Badiee Z, Asghari M, Mohammadizadeh M. Pediatr Neonatol. The Calming Effect of Maternal Breast Milk Odor on Premature Infants. May 22, 2013.

[36] Klokker M, Vesterhauge S, Jansen EC. Pressure-equalizing earplugs do not prevent barotrauma on descent from $8000 \mathrm{ft}$ cabin altitude. Aviat Space Environ Med. 76:1079.2005.

[37] Duplessis C, Fothergill D, Gertner J, et al. A pilot study evaluating surfactant on eustachian tube function in divers. Mil Med. 173:1225.2008.

[38] Foster PP, Butler BD. Decompression to altitude: assumptions, experimental evidence, and future directions. J Appl Physiol. 106:678;2009.

[39] Fernau JL, Hirsch BE, Derkay C, et al. Hyperbaric oxygen therapy: effect on middle ear and eustachian tube function. Laryngoscope. 102:48;1992

[40] Goplen FK, Grønning M, Aasen T, Nordahl SH. Vestibular effects of diving - a 6-year prospective study. Occup Med (Lond) 2010; 60:43;2010.

[41] Schore AN. Affect Regulation and The Repair of the Self New York: WW Norton \& Company, Inc; 2003.
[42] Adamec R, Young B. Neuroplasticity in specific limbic system circuits may mediate specific kindling induced changes in animal affect-implications for understanding anxiety associated with epilepsy. Neurosci Biobehav Rev. Sep;24(7):705-23; 2000.

[43] Schutz LE. Broad-Perspective Perceptual Disorder of the Right Hemisphere. Neuropsychology Review .Vol 15, Issue 1, pp 11-27; 2005.

[44] Glaser JP, Os J, Portegijs JM, Myin-Germeys I. Childhood trauma and emotional reactivity to daily life stress in adult frequent attenders of general practitioners. Journal of Psychosomatic Research. Pages 229-236Volume 61, Issue $2 ; 2006$.

[45] Evans L, McHugh T,Hopwood M, Watt C.Chronic posttraumatic stress disorder and family functioning of Vietnam veterans and their partners.Australian and New Zealand Journal of Psychiatry.Vol 37, Issue 6, pages 765-772; 2003.

[46] Kehoe P, Shoemaker WJ, Triano L, Hoffman J, Arons C. Repeated isolation in the neonatal rat. Behavioral Neuroscience. Dec;110(6):1435-44; 1996.

[47] Knickmeyer RC, Gouttard S, Kang C, Evans D, Wilber K, Keith Smith J, Hamer RM, Lin W, Gerig G, Gilmore JH. A Structural MRI Study of Human Brain Development from Birth to 2 Years. J Neurosci. 28(47): 12176-12182; 2008.

[48] Gadea M, Gomez C, González-Bono E, Espert R, Salvador A. Increased cortisol and decreased right ear advantage (REA) in dichotic listening following a negative mood induction. Psychoneuroendocrinology. Volume 30, Issue 2,129-138; 2005.

[49] Schuetze P, Reid H M. Emotional lateralization in the second year of life: Evidence from oral asymmetries. Laterality. 2005.

[50] Schore AN, Affect Regulation and the Origin of the Self: The Neurobiology of emotional Development. Lawrence Erlbaum Associates.1994.

[51] Gogate LJ, Walker Andrews AS, Bahrick LE. The intersensory origins of word comprehension: an ecological -dynamic systems view. Developmental Science.4:1, 1 $37 ; 2001$.

[52] Ovtscharoff W, Braun K. Maternal separation and social isolation modulate the postnatal development of synaptic composition in the infralimbic cortex of Octodon degus. Neuroscience.;104(1):33-40; 2001.

[53] Gutowitz S, Weber K, Kaciuban S, Colern R, Papa L, Giardano P. Middle ear pressure and symptoms after sky diving. Aviation Space and Environment Medicine.79 (5):533 -6; 2008.

[54] Weiss MH, Frost O. May children with otitis media with effusion safely fly? Clin Paediatr. 26: 567-8;1987.

[55] Stevens B, Johnston CC, Petryshen P, Taddio A. Premature infant pain profile: development and initial validation. Clin J Pain. 12:13-22; 1996. 